\title{
Effects of Methionine and Related Compounds on Plasma Cholesterol Level in Rats Fed a High Cholesterol Diet
}

\author{
Kimio SugiYama, Hiroyuki AKaI, and Keiichiro MUramatsu ${ }^{1}$ \\ Laboratory of Food and Nutrition, Department of Agricultural Chemistry, \\ Faculty of Agriculture, Shizuoka University, \\ Ohya 836, Shizuoka 422, Japan
}

(Received June 14, 1986)

\begin{abstract}
Summary The comparative effects of methionine and its structurally and metabolically related compounds on plasma cholesterol level were investigated with rats fed a high cholesterol diet. The plasma cholesterol level was significantly enhanced by the dietary addition of methyl compounds such as L-methionine, D-methionine, choline and betaine. On the other hand, the intermediary metabolites of methionine such as homocystine, cysteine and 3-methylthiopropionate reduced plasma cholesterol. $S$-Methyl-L-cysteine and dimethylglycine had no significant effect. The plasma cholesterol-elevating effects of methionine, betaine and histidine were all prevented, more or less, by the concurrent addition of glycine to the diet, suggesting the existence of a common mechanism for their effects. The results support a possibility that the plasma cholesterolelevating efficacy of methionine is attributable to its methyl group.

Key Words cholesterol, methionine, sulfur amino acids, methyl compounds, glycine, choline, histidine
\end{abstract}

It has been shown that plasma cholesterol level is influenced by the kind and amount of dietary protein in experimental animals and humans $(1-4)$. The underlying mechanism by which dietary protein affects plasma cholesterol level remains obscure. Previously we provided some evidence for the significant participation of methionine, cystine and glycine residues of dietary protein in plasma cholesterol regulation in rats fed a high cholesterol diet (5-8). Of great interest is the differential effect of methionine and cystine; methionine enhances plasma cholesterol level while cystine lowers it $(5,7)$. Besides cholesterol metabolism, there have been reported differential effects of dietary methionine and cysteine on various metabolic activities in the rat $(9,10)$. This difference may be accounted for by the following points: (a) unlike cysteine, methionine possesses a methyl group which is readily converted to various methyl compounds through $S$-adenosylmethionine, and (b) methionine is

\footnotetext{
1 杉山公男，赤井弘幸，村松敬一郎
} 
not necessarily metabolized to form cysteine; methionine can be metabolized via transamination pathway as well as transsulfuration pathway $(11,12)$.

In the present study, the effects of methionine and its structurally and metabolically related compounds on plasma cholesterol concentrations were compared in order to obtain further insights into the reason for the differential effect of methionine and cysteine. Interacting effects of glycine, which was shown to prevent hypercholesterolemia $(7,13)$, and plasma cholesterol-elevating compounds were also investigated.

\section{MATERIALS AND METHODS}

Animals and diets. Male rats of the Wistar strain, initially weighing about $90 \mathrm{~g}$ were used. The animals were individually housed in suspended wire cages and were kept in a temperature-controlled room $\left(24^{\circ} \mathrm{C}\right)$ operated on a 12-h cycle of light (06:00 to 18:00) and dark. Experimental diets and water were supplied ad libitum for 3 weeks. The composition of the basal diet containing cholesterol was as follows $(\%)$ : casein, 25; sucrose, 15; lard, 15; corn oil, 2; salt mixture (14), 5; vitamin mixture (14), 1; choline chloride, 0.2; cholesterol, 1; sodium cholate, 0.25; and corn starch to 100 . The basal diet also contained 2,700 IU vitamin A, $230 \mathrm{IU}$ vitamin $\mathrm{D}_{3}$ and $12 \mathrm{mg}$ vitamin E per $100 \mathrm{~g}$. Dietary additions were carried out at the expense of starch. At the end of the feeding period, food was removed at 24:00 and animals were sacrificed to obtain blood plasma and liver between 11:00 and 12:00 on the next day.

Analytical methods. The total lipids of the liver were extracted by the method of Folch et al.(15) and measured gravimetrically. The total cholesterol concentration of plasma and liver was determined by the method of Zak (16). High density lipoprotein (HDL) was separated by the heparin-Mn precipitation method (17) followed by the determination of HDL-cholesterol. The concentrations of plasma triglyceride, phospholipid and HDL-cholesterol were measured enzymatically with commercial kits (Wako Pure Chemical Ind., Osaka). Urine collected from animals kept in metabolic cages for 2 days (19th and 20th days) was deproteinized with sulfosalicylic acid at a final concentration of $3 \%$. An aliquot of each liver (about $2 \mathrm{~g}$ ) was homogenized with 3 volumes of $4 \%$ sulfosalicylic acid, followed by centrifugation at $10,000 \times g$ for $20 \mathrm{~min}$. The concentration of free amino acids in urine and liver was determined with amino acid autoanalyzer (Hitachi 835 type). All chemicals used were of reagent grade.

Statistical analysis. Experimental data were analyzed statistically by using one-way analysis of variance. When the $F$ test was significant, comparisons were made using the least significant difference (LSD) test to determine which pairs of means were significantly different at $p<0.05$ (18). 


\section{RESULTS}

Comparison of the effect of methionine and related compounds on plasma cholesterol (experiment 1)

Table 1 shows the growth, food consumption, liver weight and liver lipid content of rats fed the basal diet or diets supplemented with $\mathrm{L}$-methionine or related compounds at the same level as $0.8 \%$ methionine on the molar basis. The dietary addition of several compounds depressed body weight gain and food intake, but the depressions were not so intense except for $S$-methyl-L-cysteine. The contents of cholesterol and total lipids in the liver were decreased prominently by the addition of L-cysteine, 3-methylthiopropionate and $S$-methyl-L-cysteine. As shown in Table 2 , the plasma total cholesterol level was significantly increased by the dietary addition of L-methionine, D-methionine, choline and betaine, and was significantly decreased by the addition of DL-homocystine, L-cysteine and 3-methylthiopropionate. $S$-Methyl-L-cysteine and $N, N$-dimethylglycine had no significant effect. The proportion of HDL-cholesterol to the total cholesterol was greatly elevated in the groups with low plasma total cholesterol levels. The plasma phospholipid level changed in a similar manner to the plasma total cholesterol.

Effects of glycine on hypercholesterolemia induced by methionine, betaine and histidine (experiment 2)

To obtain insight into the mechanism by which a higher plasma cholesterol level is induced, the preventive effects of glycine on the hypercholesterolemia caused by L-methionine, betaine and L-histidine were compared. Table 3 shows the growth, food consumption, liver weight and liver lipid content of rats fed the basal diet or diets supplemented with methionine, betaine, histidine and/or glycine. There was no large difference in body weight gain and food intake among the groups. The dietary addition of histidine led to the enlargement of relative liver size irrespective of the concurrent addition of glycine. The addition of methionine, betaine and histidine decreased the contents of cholesterol and total lipids in the liver. Although the addition of glycine alone had no such effect, the liver cholesterol-decreasing effect of methionine, betaine and histidine was enhanced by the concurrent addition of glycine. Table 4 summarizes plasma lipid concentrations. The plasma total cholesterol level was enhanced by the dietary addition of methionine, betaine and histidine. Although the addition of glycine alone had a tendency to lower plasma total cholesterol, greater effects were observed when glycine was added together with other compounds. The concurrent addition of glycine also prevented the enhancement of plasma phospholipid concentration. Glycine had no obvious effect on the concentration of HDL-cholesterol and triglyceride.

Table 5 shows the concentration of free taurine and glycine in the liver and the urinary excretion of taurine. Dietary supplementation with methionine or methionine plus glycine increased liver taurine concentration, whereas betaine or histidine supplementation slightly decreased the taurine concentration. There was 


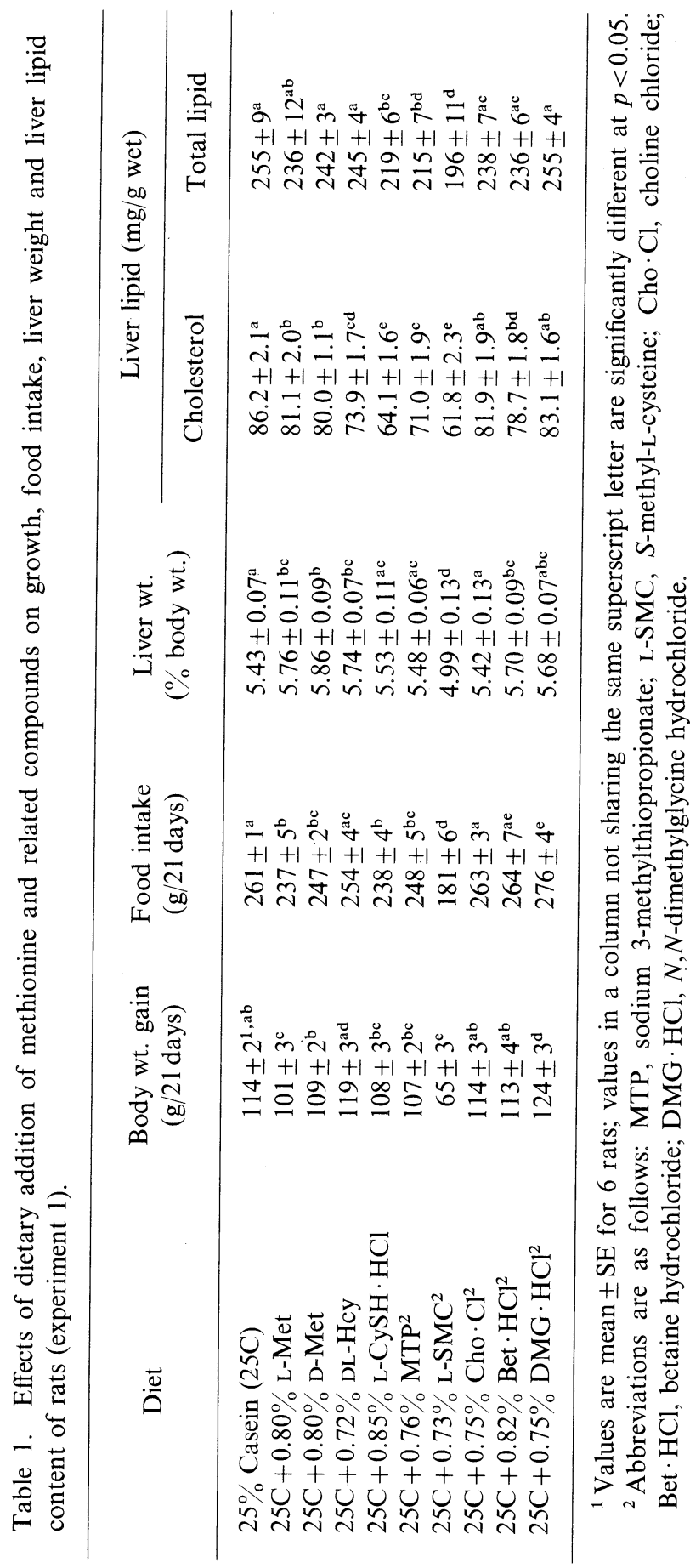




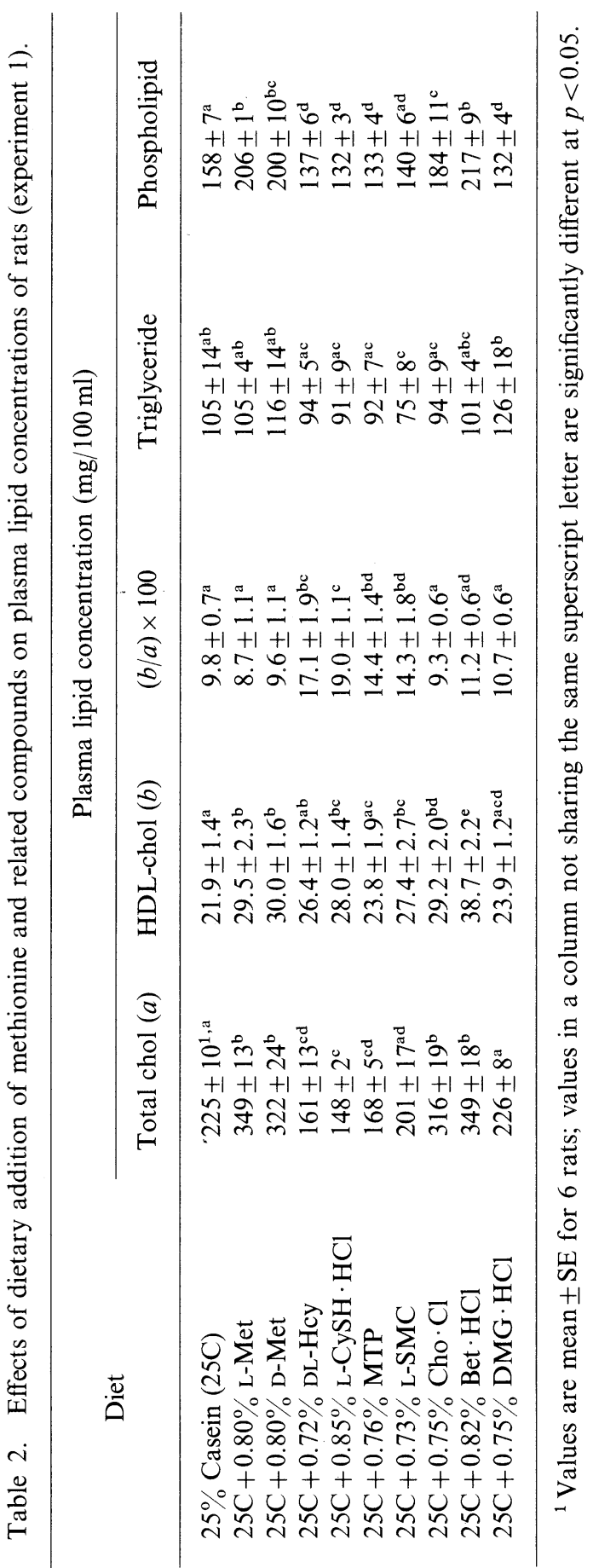




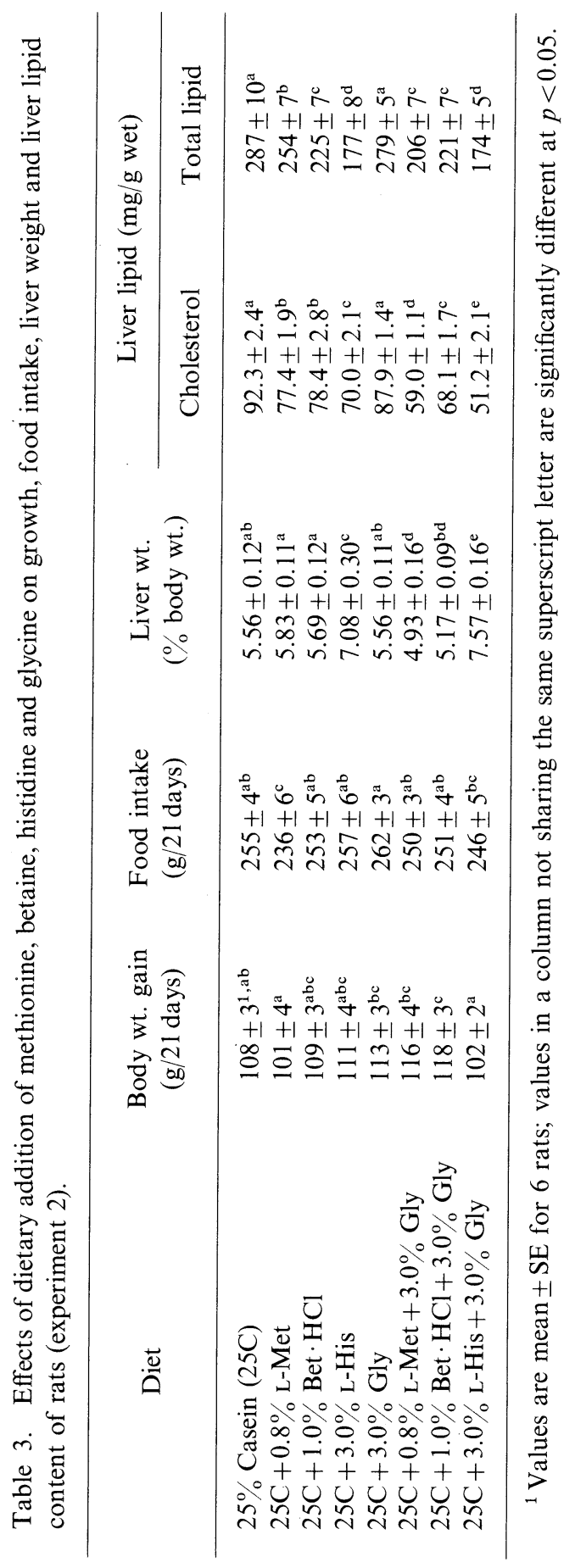

J. Nutr. Sci. Vitaminol. 


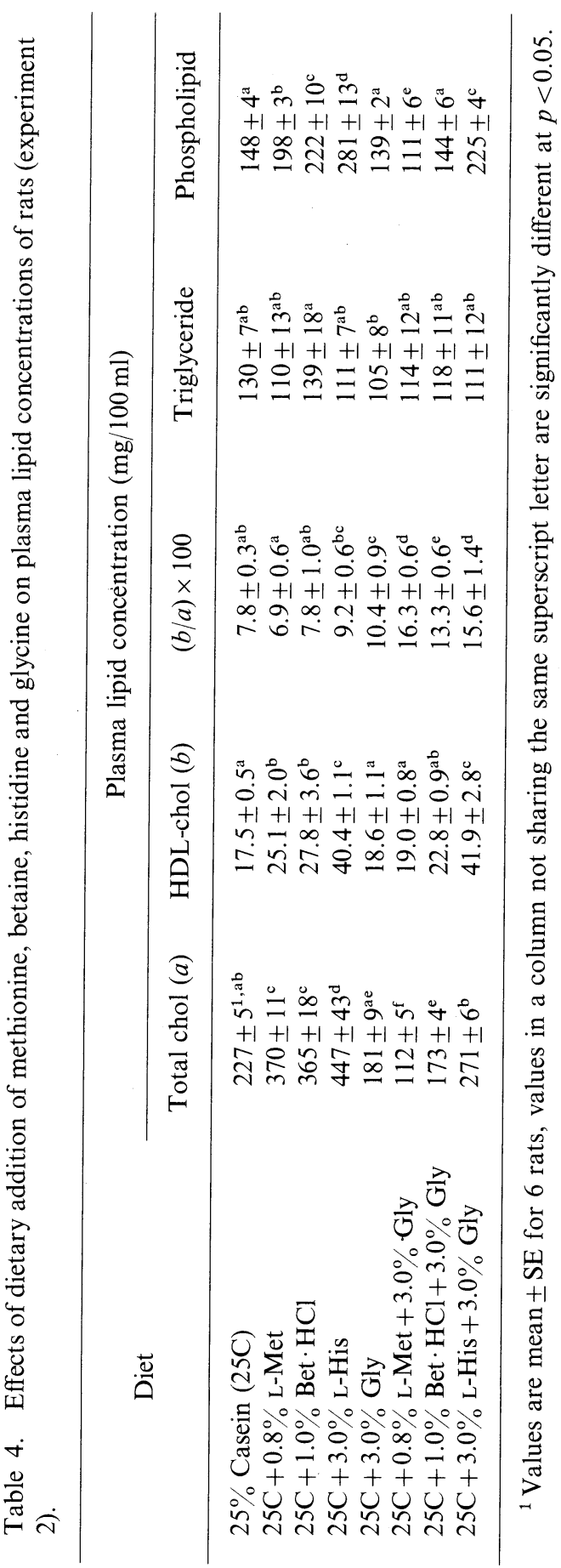


Table 5. Effects of dietary addition of methionine, betaine, histidine and glycine on urinary taurine excretion and liver amino acid concentrations (experiment 2).

\begin{tabular}{|c|c|c|c|}
\hline \multirow{2}{*}{ Diet } & \multicolumn{2}{|c|}{$\begin{array}{l}\text { Amino acid concn. in liver } \\
\qquad(\mu \mathrm{mol} / \mathrm{g})\end{array}$} & \multirow{2}{*}{$\begin{array}{l}\text { Taurine excreted } \\
\text { in urine } \\
(\mu \mathrm{mol} / 2 \text { days })\end{array}$} \\
\hline & Taurine & Glycine & \\
\hline $25 \%$ Casein $(25 \mathrm{C})$ & $2.28 \pm 0.08^{1, \mathrm{a}}$ & $1.13 \pm 0.05^{1, \mathrm{ab}}$ & $4.1 \pm 0.3^{2, \mathrm{a}}$ \\
\hline $25 \mathrm{C}+0.8 \%$ L-Met & $6.42 \pm 0.16^{\mathrm{b}}$ & $1.25 \pm 0.02^{\mathrm{ac}}$ & $32.5 \pm 6.3^{\mathrm{b}}$ \\
\hline $25 \mathrm{C}+1.0 \% \mathrm{Bet} \cdot \mathrm{HCl}$ & $1.22 \pm 0.25^{\mathrm{c}}$ & $1.06 \pm 0.05^{\mathrm{bd}}$ & $4.4 \pm 0.4^{\mathrm{a}}$ \\
\hline $25 \mathrm{C}+3.0 \% \mathrm{~L}-\mathrm{His}$ & $1.59 \pm 0.07^{\mathrm{cd}}$ & $0.94 \pm 0.02^{\mathrm{d}}$ & $7.5 \pm 1.0^{\mathrm{a}}$ \\
\hline $25 \mathrm{C}+3.0 \%$ Gly & $2.30 \pm 0.06^{\mathrm{a}}$ & $1.72 \pm 0.06^{\mathrm{e}}$ & $6.8 \pm 0.7^{\mathrm{a}}$ \\
\hline $25 \mathrm{C}+0.8 \%$ L-Met $+3.0 \%$ Gly & $6.88 \pm 0.17^{\mathrm{e}}$ & $1.54 \pm 0.07^{\mathrm{f}}$ & $120.5 \pm 11.2^{\mathrm{c}}$ \\
\hline $25 \mathrm{C}+1.0 \%$ Bet $\cdot \mathrm{HCl}+3.0 \%$ Gly & $1.82 \pm 0.08^{\mathrm{d}}$ & $1.40 \pm 0.09^{\mathrm{cf}}$ & $5.8 \pm 0.6^{\mathrm{a}}$ \\
\hline $25 \mathrm{C}+3.0 \%$ L-His $+3.0 \%$ Gly & $1.36 \pm 0.03^{\mathrm{c}}$ & $1.16 \pm 0.05^{\mathrm{ab}}$ & $8.7 \pm 1.7^{\mathrm{a}}$ \\
\hline
\end{tabular}

${ }^{1}$ Values are mean \pm SE for 3 determinations of the pooled samples of 2 rats. ${ }^{2}$ Values are mean \pm SE for 6 rats. Values in a column not sharing the same superscript letter are significantly different at $p<0.05$.

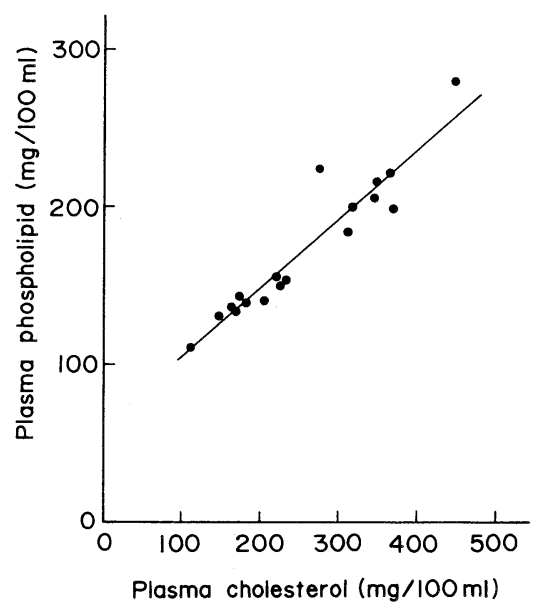

Fig. 1. Relationship between plasma total cholesterol and plasma phospholipid concentrations in experiments 1 and 2. Each point represents the mean value of 6 rats.

no large change in glycine concentration. The urinary excretion of taurine was increased by dietary supplementation with methionine and this was further enhanced by the concurrent addition of glycine. Figure 1 illustrates the relationship between plasma total cholesterol and plasma phospholipid concentrations in both experiments. There was a highly significant correlation between both lipid concentrations $(r=0.931, p<0.001)$. 


\section{DISCUSSION}

Several earlier reports have shown the plasma cholesterol-lowering effect of methionine in experimental animals fed low protein diets(19-21) or fed a methionine-deficient diet (19). When methionine was added to a diet containing adequate protein, the effect of methionine diminished (21), suggesting the dietary protein level-dependency of the effect of methionine. In accordance with this, our previous report demonstrated that dietary addition of $0.75 \%$ methionine decreased plasma cholesterol level for $10 \%$ casein diet, but it increased plasma cholesterol level for 25 and $50 \%$ casein diets (7). Thus, the effect of methionine appears to be influenced by the the dietary conditions of animals.

As shown in Fig. 2, methionine is known to be metabolized by two metabolic pathways, i.e., transsulfuration and transamination pathways $(11,12)$. However, the relative contribution of each pathway, especially of the transamination pathway, to the methionine metabolism remains unclear $(22,23)$. It is of interest to know which pathway is responsible for the effect of methionine on plasma cholesterol level since the effect can be considered to be associated with the metabolism of methionine. It is well known that D-isomer of methionine can be utilized in place of L-isomer for the growth of animals (24). Approximately equivalent effects of both isomers were also observed in the present study; the plasma cholesterol level was enhanced by the dietary addition of D-methionine as well as L-methionine to a similar extent. These suggest the same metabolic fate of both isomers, at least under the present experimental conditions. If the metabolism of methionine by the transamination pathway was related to the effect of methionine, the effect of 3-methylthiopropionate, an intermediary metabolite in the transamination pathway (25), might be comparable to that of methionine. However, the results did not support this assumption; 3-methylthiopropionate did not enhance plasma cholesterol level but rather decreased it. Thus, the results support an alternative possibility that the plasma cholesterol-elevating effect of methionine

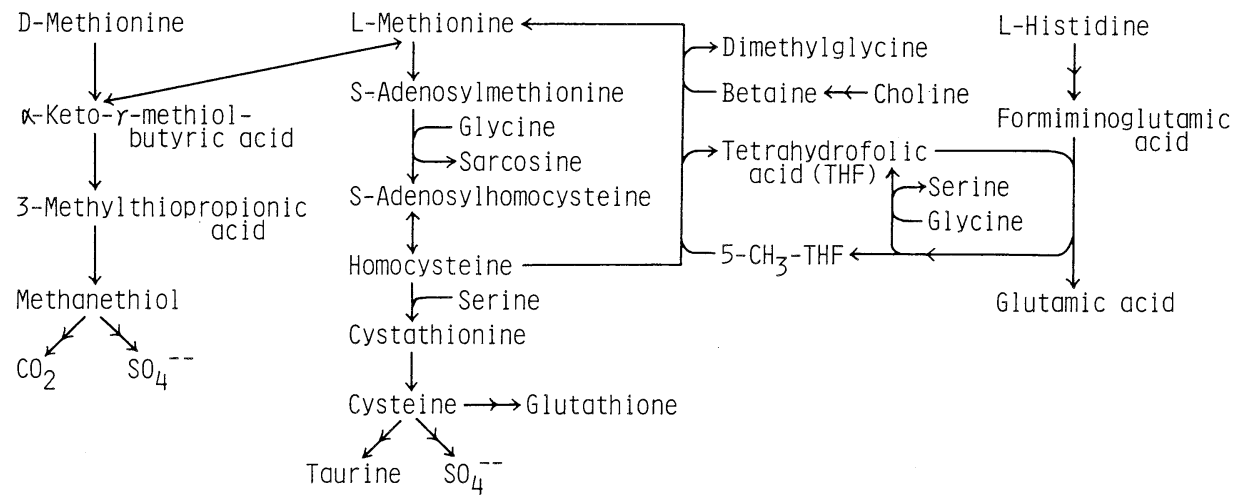

Fig. 2. Pathways of methionine metabolism in mammals.

Vol. 32, No. 5, 1986 
is mainly associated with the metabolism of methionine by the transsulfuration pathway.

The plasma cholesterol level was elevated not only by methionine but also by methyl compounds such as choline and betaine. By contrast, Abe and Kaneda (26) have reported the plasma cholesterol-lowering effect of some betaines in rats fed a high cholesterol diet. This discrepancy of the effect of betaine may be attributable to the difference in the kind of betaine used and/or in the addition level of betaine. Earlier studies have demonstrated that the serum cholesterol levels of rats fed choline-deficient diets were lower than those of rats fed choline-sufficient diets $(20,27,28)$. The cholesterol-lowering effect of choline-deficiency could be counteracted by the dietary addition of methionine and betaine (20). Since choline and betaine can be synthesized in the liver by use of the methyl group of methionine in the transsulfuration pathway, the results obtained here support the assumption that the cholesterol-elevating effect of methionine is attributable to its methyl group (20). Although $S$-methyl-L-cysteine and $N, N$-dimethylglycine contain methyl group, they did not elevate plasma cholesterol level. This might be related to the following metabolic characteristics of these compounds; $S$-methyl-L-cysteine cannot enter the transsulfuration pathway (29), and unlike choline and betaine $N, N$ dimethylglycine had no lipotropic action. Thus, only methyl compounds from which choline can be synthesized appear to lead to a higher plasma cholesterol level.

In contrast, it is reasonable to consider that the non-methyl portion of the methionine molecule has a cholesterol-lowering efficacy since non-methyl derivatives of methionine such as homocystine and cysteine had a cholesterol-lowering effect and taurine is also known to have a cholesterol-lowering effect $(20,26,30)$. The dietary addition of methionine increased urinary excretion and liver concentration of taurine, but it did not lead to the reduction of plasma cholesterol level unless glycine was concurrently added to the diet. This appears to suggest that the hypocholesterolemic effect of the non-methyl portion of methionine is not so strong as the hypercholesterolemic effect of the methyl group.

It has been reported that the metabolism of methionine is accelerated by dietary glycine especially when the glycine is added to the diet high in methionine (31). Increased urinary excretion of taurine in rats fed a diet supplemented with methionine plus glycine appears to be another evidence for the effect of glycine. One of the participations of glycine in methionine metabolism is accepting the methyl group of $S$-adenosylmethionine as the substrate for glycine $N$ methyltransferase (32). Previously we reported that the dietary addition of methionine plus glycine resulted in a significant reduction of plasma cholesterol while the addition of methionine alone caused a significant enhancement (7). The results of experiment 2 support the previous finding. Furthermore, glycine also prevented the enhancement of plasma cholesterol induced by betaine and histidine. It has been reported that the diet containing high levels of histidine can increase plasma cholesterol levels in experimental animals (32-35), but the underlying mechanism has not been fully elucidated. Although unlike methionine and betaine, histidine 
does not possess a methyl group, it can provide a $C_{1}$ unit which is converted to an active methyl group in the form of 5-methyltetrahydrofolic acid. Thus, taking into consideration the effect of glycine on histidine-induced hypercholesterolemia, it is possible that the hypercholesterolemic effect of histidine may be attributable, at least in part, to $\mathrm{C}_{1}$ unit derived from the amino acid.

There was no consistent relationship between plasma and liver cholesterol levels. This suggests that alterations in plasma cholesterol level is not entirely ascribable to the transport of cholesterol between liver and plasma under our experimental conditions. In general, choline-deficiency leads to a decrease in plasma lipids and to an increase in liver lipids. However, it was also reported that when rats were fed a choline-deficient diet containing cholesterol, liver cholesterol content was rather decreased while fatty liver was developed, suggesting the existence of a lipotropic activity-independent effect of choline on liver cholesterol content (20). Thus, the effect of lipotropic compounds on liver cholesterol is complicated.

Parallel changes have been often observed in the plasma concentrations of cholesterol and phospholipid. The results obtained here also showed such a relationship (Fig. 1). It is of interest to know whether changes in plasma phospholipid level is related to the cause or merely to the result of changes in plasma cholesterol level. Taking into consideration that choline-containing phospholipids comprise over $90 \%$ of plasma total phospholipids in the rat and that choline or other compounds which can be utilized for choline synthesis induced the enhancement of plasma cholesterol, the former seems to be more probable.

\section{REFERENCES}

1) Carroll, K. K., and Hamilton, R. M. G. (1975): Effect of dietary protein and carbohydrate on plasma cholesterol in relation to atherosclerosis. J. Food Sci., 40, 1823.

2) Kritchevsky, D. (1979): Vegetable protein and atherosclerosis. J. Am. Oil Chem. Soc., 56, 135-140.

3) Gibney, M. J. (1982): Hypocholesterolemic effect of soya-bean proteins. Proc. Nutr. Soc., 41, 19-26.

4) Sugano, M. (1983): Hypocholesterolemic effect of plant protein in relation to animal protein: Mechanism of action, in Animal and Vegetable Proteins in Lipid Metabolism and Atherosclerosis, ed. by Gibney, M. J., and Kritchevsky, D., Alan R. Liss, Inc., New York, pp. 51-81.

5) Sugiyama, K., Kushima, Y., and Muramatsu, K. (1984): Effect of methionine, cystine and taurine on plasma cholesterol level in rats fed a high cholesterol diet. Agric. Biol. Chem., 48, 2897-2899.

6) Sugiyama, K., Ozawa, M., and Muramatsu, K. (1985): Dietary sulfur-containing amino acids and glycine as determinant factors in plasma cholesterol regulation in growing rats. J. Nutr. Sci. Vitaminol., 31, 121-125.

7) Sugiyama, K., Kushima, Y., and Muramatsu, K. (1985): Effects of sulfur-containing amino acids and glycine on plasma cholesterol level in rats fed on a high cholesterol diet. Agric. Biol. Chem., 49, 3455-3461.

8) Sugiyama, K., Ohkawa, S., and Muramatsu, K. (1986): Relationship between amino Vol. 32, No. 5, 1986 
acid composition of diet and plasma cholesterol level in growing rats fed a high cholesterol diet. J. Nutr. Sci. Vitaminol., 32, 413-423.

9) Smith, J. T., Acuff, R. V., Bittle J. B., and Gilbert, M. L. (1983): A metabolic comparison of cysteine and methionine supplements in the diet of a rat. J. Nutr., 113, 222-227.

10) Acuff, R. V., and Smith, J. T. (1983): The influence of cysteine and methionine supplements on polyamine biosynthesis in the rat. J. Nutr., 113, 2295-2299.

11) Cooper, A. J. L. (1983): Biochemistry of sulfur-containing amino acids. Annu. Rev. Biochem., 52, 187-222.

12) Benevenga, N. J., and Steele, R. D. (1984): Adverse effects of excessive consumption of amino acids. Annu. Rev. Nutr., 4, 157-181.

13) Katan, M. B., Vroomen, L. H. M., and Hermus, R. J. J. (1982): Reduction of caseininduced hypercholesterolemia and atherosclerosis in rabbits and rats by dietary glycine, arginine and alanine. Atherosclerosis, 43, 381-391.

14) Harper, A. E. (1959): Amino acid balance and imbalance. Part I. Dietary level of protein and amino acid imbalance. J. Nutr., 68, 405-424.

15) Folch, J., Lees, M., and Sloane Stanley, G. H. (1957): A simple method for the isolation and purification of total lipides from animal tissues. J. Biol. Chem., 226, 497-509.

16) Zak, B. (1957): Simple rapid microtechnic for serum total cholesterol. Am. J. Clin. Pathol., 27, 583-588.

17) Burnstein, M., Scholnick, H. R., and Morfin, R. (1970): Rapid method for the isolation of lipoproteins from human serum by precipitation with polyanions. J. Lipid Res., 11, 583-595.

18) Snedecor, G. W., and Cochran, W. G. (1967): Statistical methods, 6th Ed., Iowa State University Press, Ames, Iowa (Japanese edition), Chapt. 10.

19) Fillios, L. C., and Mann, G. V. (1954): Influence of sulfur amino acid deficiency on cholesterol metabolism. Metabolism, 3, 16-26.

20) Seidel, J. C., Nath, N., and Harper, A. E. (1960): Diet and cholesterolemia: V. effects of sulfur-containing amino acids and protein. J. Lipid Res., 1, 474-481.

21) Leveille, G. A., Shockley, J. W., and Sauberlich, H. E. (1962): Influence of dietary protein level and amino acids on plasma cholesterol of the growing chicks. J. Nutr., 76, 321-324.

22) Fau, D., Bois-Joyeux, B., Chanez, M., Delhomme, B., and Peret, J. (1981): Adaptation of hepatic enzyme activities to methionine excess. Reprod. Nutr. Dévelop., 21, 519-529.

23) Finkelstein, J. D., and Martin, J. J. (1986): Methionine metabolism in mammals. $J$. Biol. Chem., 261, 1582-1587.

24) Meister, A. (1965): The role of amino acids in nutrition, in Biochemistry of the Amino Acids, Vol. 1, 2nd Ed., Academic Press, New York, pp. 201-230.

25) Steele, R. D., and Benevenga, N. J. (1978): Identification of 3-methylthiopropionic acid as an intermediate in mammalian methionine metabolism in rats. J. Biol. Chem., 253, 7844-7850.

26) Abe, S., and Kaneda, T. (1975): Effect of betaines and taurine and its derivatives on plasma cholesterol levels in rats. Nippon Eiyō Shokuryō Gakkaishi (J. Jpn. Soc. Nutr. Food Sci.), 28, 125-128.

27) Ridout, J. H., Patterson, J. M., Lucas, C. C., and Best, C. H. (1954): Effect of lipotropic substances on the cholesterol content of the serum of rats. Biochem. J., 58, 306-312.

28) Olson, R. E., Jablonski, J. R, and Taylor, E. (1958): The effect of dietary protein, fat, and choline upon the serum lipids and lipoproteins of the rat. Am. J. Clin. Nutr., 6, 111118. 
29) Lombardini, J. B., Coulter, A. W., and Talalay, P. (1970): Analogues of methionine as substrates and inhibitors of the methionine adenosyltransferase reaction. Mol. Pharmacol., 6, 481-499.

30) Hermann, R. G. (1959): Effect of taurine, glycine and $\beta$-sitosterol on serum and tissue cholesterol in the rat and rabbit. Circ. Res., 7, 224-227.

31) Benevenga, N. J., and Harper, A. E. (1970): Effect of glycine and serine on methionine metabolism in rats fed diets high in methionine. J. Nutr., 100, 1205-1214.

32) Heady, J. E., and Kerr, S. J. (1973): Purification and characterization of glycine $N$ methyltransferase. J. Biol. Chem., 248, 69-72.

33) Geison, R. L., and Waisman, H. A. (1970): Plasma and tissue cholesterol and lipid levels in rabbits on L-histidine-supplemented diets. Proc. Soc. Exp. Biol. Med., 133, 234-237.

34) Solomon, J. K., and Geison, R. L. (1978): Effect of excess dietary L-histidine on plasma cholesterol levels in weanling rats. J. Nutr., 108, 936-943.

35) Aoyama, Y., Yoshida, A., and Ashida, K. (1983): Changes in lipids in liver and serum of rats fed a histidine-excess diet. Nutr. Rep. Int., 28, 643-651. 